\title{
Arbor
}

\section{Dramaturgia femenina fin de siglo. Estado de la cuestión}

\section{Virtudes Serrano}

Arbor CLXXVII, 699-700 (Marzo-Abril 2004), 561-572 pp.

La intención de estas páginas se centra en componer el panorama de la expresión pública de la incorporación de la mujer a la escritura y la práctica de la dirección de escena desde la década de los ochenta del siglo XX hasta el momento actual. Traemos a colación algunos de los hitos que desde 1983 van sirviendo para establecer el estado de la cuestión de una dramaturgia que, a las dificultades que conlleva un género como el dramático, a caballo entre la literatura y el espectáculo; entre el arte y la empresa, añade la de estar realizado por mujeres, a quienes les supone un mayor esfuerzo que a los hombres el ser reconocidas y valoradas. Así lo manifestaban las autoras en 1984 y en el mismo sentido se expresan las actuales representantes de los últimos colectivos aparecidos en la escena española.

Los primeros años del siglo XXI se han convertido en un buen momento para reflexionar sobre aconteceres del periodo histórico que no ha hecho más que terminar y para establecer, en la medida de lo posible, el balance de los logros alcanzados en los distintos ámbitos de la actividad humana. Dentro de la parcela que en el conjunto de tal actividad le corresponde a las acciones de carácter socio-cultural nos concierne el enfoque de uno de sus aspectos, el del espacio que las mujeres han conquistado dentro del panorama teatral desde la perspectiva de la autoría del texto dramático y de la dirección de obras propias o ajenas. 
Aunque desde hace años venimos ocupándonos de la presencia de las autoras en el paisaje público de la dramaturgia española y, por tanto, muchas de nuestras consideraciones están expresadas con anterioridad, acometemos ahora la tarea de establecer, con la perspectiva que la historia ofrece, una recapitulación sobre la presencia femenina en nuestra dramaturgia fin de siglo y de perfilar algunas de las facetas esbozadas a lo largo de la trayectoria recorrida por las autoras desde los años ochenta hasta hoy.

El cambio de régimen político operado a la muerte del general Franco en 1975 y la emancipación de una sociedad tanto tiempo amordazada favorecieron la presencia de las individualidades y con ello se concedió voz pública a la mujer. Con la libertad de la voz llegó la exhibición de los deseos hasta entonces ocultos por las normas explícitas e implícitas que los mantenían silenciados. Las mujeres tomaron las calles para exigir su derecho al trabajo en igualdad, a la libre asociación, a la sexualidad y, junto a cuestiones de tan indiscutible calado, algunas pedían también autonomía para gozar del espacio público del teatro, no sólo como actrices, propiedad de la que sí disfrutaban, sino como autoras representadas y publicadas, en las mismas condiciones que los hombres que venían siendo los artífices del canon de la literatura dramática y los ocupantes habituales de la escena.

Califiqué la década de los ochenta del pasado siglo como la del renacer de la dramaturgia femenina en España porque desde 1983 las autoras comenzaron, no sin esfuerzo, a mostrar su trabajo, mediante la edición y el montaje de sus obras, dirigidas en ocasiones por ellas mismas; lucharon por hacer oír su voz en las publicaciones especializadas en teatro y por conquistar un lugar en la historia de literaria.

Es cierto que la presencia femenina en la autoría teatral no constituye una novedad de las últimas dos décadas del siglo XX; ya en 1903, Manuel Serrano Sanz ${ }^{1}$ catalogó más de una treintena de autoras teatrales, algunas editadas en la actualidad en las colecciones de textos de la Asociación de Directores de Escena; durante el primer tercio del siglo XX muchas mujeres dedicaron su vida y sus energías a la actividad teatral, tanto en el ámbito de la autoría como en el de la gestión, aunque su esfuerzo quedó cubierto, en la mayor parte de los casos, por el brillo de sus compañeros de generación e incluso de vida, tal como ocurrió con María de la O Lejárraga y Gregorio Martínez Sierra ${ }^{2}$. Algunos nombres pasaron inmediatamente a formar parte de la historia del teatro, como el de doña María Guerrero o el de Margarita Xirgu, pero casi ha tenido que transcurrir el siglo hasta que la consideración crítica y teórica de la mujer au- 
Dramaturgia femenina fin de siglo. Estado de la cuestión

tora teatral o directora de escena se haya convertido en algo habitual y no en una excepción. Por ello es interesante contrastar las opiniones fechadas a comienzos de los años ochenta sobre mujeres directoras y autoras con los resultados que desde 1996 viene publicando la ADE en sus extensos catálogos ${ }^{3}$.

Como indicábamos, fue en la década de los ochenta cuando tal normalización se inicia, en algunos casos con poca fortuna (tómese como ejemplo la corta vida del Premio Lisístrata que se concedía en el Festival Internacional de Teatro de Sitges, nacido en 1980, cuando era director del Festival Ricard Salvat, y desaparecido en 1983 por recortes económicos impuestos por el Patronato). Fue también en 1982 cuando Salvat dirigió, para ser representado en Atenas, el montaje Dones i Catalunya, cuyo texto escribieron seis escritoras catalanas ${ }^{4}$. En este año se recupera la imagen dramatúrgica de la periodista y escritora Teresa Gracia, que partió al exilio en 1939, con cuatro años de edad, y desde aquel alejamiento forzoso compuso una obra dramática que rescata en la escritura de una autora adulta la memoria de la niñez exiliada. Las republicanas se publicó en 1982 y diez años después han visto la luz Casas viejas y Una mañana, una tarde y una vida de la señorita Pura ${ }^{5}$.

En 1983, la librería La Avispa edita Un olor a ámbar, primera obra de Concha Romero, prologada por Patricia W. O'Connor, especialista en teatro español contemporáneo y directora entonces de la revista Estreno ${ }^{6}$; el mismo año, Carmen Resino, cuyo primer texto teatral, El presidente, apareció en 1968, publica Ulises no vuelve, que había recibido un accésit del Premio Lope de Vega en 19747; y a la joven autora María Manuela Reina se le concede el Premio SGAE por El navegante. Es evidente que algo ha movilizado a las creadoras cuando, por primera vez (Romero, Reina), o como esperanzado nuevo intento (Resino), deciden abandonar el recinto interior y pasar al público.

El año siguiente resulta definitivo para el conocimiento y reconocimiento de las autoras, al menos entre los especialistas en materia teatral, porque Estreno les dedica monográficamente su número de otoño. Bien es cierto que la nómina de escritoras referidas y entrevistadas en ese espacio es heterogénea y que algunas de las que allí aparecen no vuelven a dejarse ver después de la creación de la Asociación de Dramaturgas en 1986. En esos momentos iniciales, estaban unidas por el deseo de ser escuchadas, aunque los intereses de las participantes en esta aparición eran muy diferentes. Las páginas de Estreno congregaron a dramaturgas que venían de otra generación, como Dora Sedano, Mercedes Ballesteros, Isabel Suárez de Deza o Luisa María Linares; a la autora de 
éxito indiscutido que ya era Ana Diosdado; a narradoras reconocidas con alguna incursión en la escritura dramática (Carmen Martín Gaite o Lourdes Ortiz, quien por entonces no tenía en su haber nada más que un par de textos dramáticos). Entre las de más reciente aparición las había de clara procedencia feminista (María José Ragué-Arias y Lidia Falcón); otras cuyo feminismo emanaba de su visión del mundo vertida en el texto (Carmen Resino o Concha Romero); participaba también Maria Manuela Reina, la más joven y el prototipo de una escritura dramática no diferenciada de canon conservador. En estos primeros tiempos, salvo Ana Diosdado, que se manifestó libre de la sensación castrante que el intento de acceder al espacio público del teatro producía en las mujeres, las demás declaraban la dificultad de conquistar un lugar adecuado para mostrar su obra en igualdad de condiciones con los dramaturgos.

$\mathrm{Si}$ es innegable el impulso inicial que reciben desde este momento, gracias al interés que despiertan en el hispanismo norteamericano, también es cierto que la visión del mundo de la sociedad española de los ochenta está cambiando y que las mujeres van hallando ciertos espacios en su propio entorno. En 1984, bajo el auspicio del recién inaugurado Centro Nacional de Nuevas Tendencias Escénicas (CNNTE) tiene lugar un encuentro donde se debatió sobre la nueva escritura teatral ${ }^{8}$; a pesar de que la mayor parte de los congregados eran autores, intervinieron en los debates María José Ragué y Concha Romero; y estuvieron presentes con sendas ponencias Lourdes Ortiz y Marisa Ares, que, poco después, estrenaba en el CNNTE Negro seco, cuyo texto apareció, en 1987, en la colección de dicha institución con Rotos intencionados. A pesar de su rápido tránsito por el panorama del teatro español de aquel momento, otra obra suya, Anda, empújame, tuvo cabida en la antología dedicada al teatro escrito por mujeres en España que Patricia W. O'Connor estaba preparando y que salió a la calle en $1988^{9}$. También entonces, y bajo el mismo patrocinio, se lleva a cabo un taller de escritura y dirección, guiado por Jesús Campos, en el que participaron Paloma Pedrero, Maribel Lázaro, Luis Araujo, José Manuel Arias e Ignacio del Moral. En el número 212, enero-febrero de 1986, la revista Primer Acto incluye una entrevista a los participantes y el texto de Humo de beleño, de Maribel Lázaro, ganador del Premio Calderón de la Barca del ochenta y cinco, que un año antes había recaído sobre La libertad esclava, de María Manuela Reina ${ }^{10}$. Así mismo, en 1985 tiene lugar el estreno de La llamada de Lauren, de Paloma Pedrero, que merece referencia por el escándalo que trascendió a la prensa al considerar la crítica que la obra no era adecuada, por su tema y su lenguaje dramático, a la jovencísima autora que la firmaba ${ }^{11}$. 


\section{Dramaturgia femenina fin de siglo. Estado de la cuestión}

La situación, no obstante, se va normalizando y el año 1986 supone un hito importante en el proceso de salida iniciado porque en él se funda la Asociación de Dramaturgas con la intención expresa, en palabras de Carmen Resino, que fue elegida presidenta, de «reivindicar, sin ningún tipo de tinturas ideológicas o pancartas feministas, la actividad dramatúrgica femenina y, a través del teatro, contribuir a mejorar la situación de la mujer, dentro del contexto social cuyo sistema se obstina todavía en cerrarle determinados ámbitos de actuación». La Asociación tuvo corta y agitada vida porque, como se ha indicado, las diferencias entre las autoras generaron no pocas disensiones, sobre todo entre las escritoras de tendencia feminista más radical y las que no compartían tales ideas.

En abril de 1987, la revista El Público ofrece la noticia de que «las dramaturgas se asocian». La Asociación se formalizó el 12 de marzo como respuesta a la convocatoria que un año antes había hecho Patricia W. O' Connor, en una reunión a la que asistieron más de treinta autoras. María Victoria Oliva resume los objetivos de la Asociación, a los que calificó de «más que ambiciosos»:

Promover el teatro español, en general, y el femenino en particular; incentivar el intercambio y los contactos culturales para un mayor desarrollo y divulgación del quehacer teatral; promocionar el papel de la mujer en el ámbito escénico y contribuir a su integración en la vida cultural española ${ }^{12}$.

Las dramaturgas se proponen conseguir el apoyo de organismos como el INAEM, el Instituto de la Mujer, también de reciente creación, y la Comunidad de Madrid para llevar a cabo lecturas, escenificaciones y ediciones de sus textos, así como conferencias, y todo tipo de actividades que las ayuden a darse a conocer y que les permitan participar activamente en la evolución de la sociedad y del teatro de su tiempo; bajo este impulso surge la colección Lucerna en cuyos números iniciales publican Carmen Resino y Concha Romero. Los primeros jueves de cada mes, las quince escritoras que constituyeron finalmente la Asociación se reunían en el sótano de la Librería La Avispa para leer y comentar textos y establecer estrategias de actuación; en general declaran su satisfacción por haber abierto un camino que ayudará a muchas a continuar lo que ya estaban abandonando. Los nombres de las fundadoras fueron, según figuraban en los recibos de la Asociación: Mirén Díaz de Ibarrondo, Carmen Resino, Julia Butinya Jiménez, Pilar Rodrigo, María Angélica Mayo, Pilar Pombo, Concha Romero, Ofelia Angélica Gauna, Maribel Lázaro, Carmen de Miguel Poyard, Milagros López Muñoz, Mayte Ayllón Trujillo, Carmen García Amat, Norma Bacaicoa y Paloma Pedrero. Algunas de ellas se quejan de que la falta de tiempo, limitado por sus obligaciones, 
les impide gestionar la salida a la luz de sus obras. Estamos todavía ante la cuestión debatida por las dramaturgas entrevistadas en 1984: la condición femenina y la dificultad que ello conlleva para penetrar en los espacios públicos ${ }^{13}$.

En septiembre de este mismo año Primer Acto convoca a las autoras a un coloquio moderado por Lourdes Ortiz; en él participan Yolanda García Serrano, Maribel Lázaro, Paloma Pedrero, Carmen Resino y Concha Romero ${ }^{14}$. Aunque el tema central era la Asociación, pronto se comienza a hablar de los problemas comunes al teatro, esté escrito por hombres o por mujeres, y de los conflictos específicos de la dramaturgia femenina en relación con el feminismo. Paloma Pedrero y Maribel Lázaro, que contaban con estrenos recientes y reacciones adversas de público y crítica debido a su lenguaje dramático, ilustraron con anécdotas posteriores a la representación de sus obras el tema de la falta de tolerancia existente en los críticos, todos hombres, frente a ellas, jóvenes autoras que se atrevían con contenidos como el de la identidad sexual (La llamada de Lauren...) o el ejercicio del poder por la mujer ( $L a$ fosa).

En la década de los ochenta se rubrica para el público la existencia de la mujer dramaturga en la España actual con la aparición de la antología de piezas breves publicada en 1988 por Patricia W. O' Connor. A partir de aquí, algunas historias de la literatura dramática fueron incorporando los nombres de las autoras y éstas comenzaron a formar parte de congresos y cursos donde podían mostrar su trabajo.

La década de los noventa se abre con una casi absoluta normalidad de la actividad de la mujer en todos los terrenos de lo teatral y con una creciente incorporación de autoras, en buena medida procedentes de los talleres de dramaturgia y de las lecciones sobre construcción de texto dramático que han ido proliferando y se han convertido en cantera de jóvenes creadores de ambos sexos. En 1990 desaparece la Asociación de Dramaturgas y muchas de sus componentes se integran en la recién nacida, con Alberto Miralles como presidente, Asociación de Autores de Teatro; es un paso hacia la igualdad de las escritoras en el panorama general de la escena, sin que ello signifique la anulación de un teatro feminista que denuncia los abusos sobre la mujer y defiende sus derechos contra las imposiciones del patriarcado.

En la separata del número 233 de Primer Acto se transcribe un coloquio del I Encuentro de Autores/as jóvenes organizado por el Instituto del Teatro de Asturias celebrado en Gijón en enero de 1990; en él intervienen Ernesto Caballero, Eladio de Paco, Ignacio del Moral, Guillermo Heras, Lourdes Ortiz, Paloma Pedrero, Maxi Rodríguez y Etelvino Vázquez. 
Dramaturgia femenina fin de siglo. Estado de la cuestión

Autores y autoras debaten problemas de carácter práctico: la dificultad de estrenar, la necesidad o no de ajustarse a los gustos del público, la opción entre teatro de texto o guión para crear el espectáculo; y de actitud estética: la vuelta a la concepción aristotélica de la puesta en escena, aplicada a un teatro de hoy de raíz naturalista, y la recuperación del realismo que se produce en un sector de la reciente dramaturgia.

Autoras que iniciaron su trayectoria en la década anterior ven algunas de sus obras en cartel. En 1990 tiene lugar el estreno del primer bloque de Noches de amor efimero, de Paloma Pedrero. Ella posee ya una sólida posición en el conjunto del teatro del momento, y la crítica no asesta sobre este espectáculo los inmisericordes golpes que hubo de sufrir el de 1985; recibe ese año Pilar Pombo el Premio del I Certamen de la Comunidad de Madrid por No nos escribas más canciones, estrenada en Londres en 1991, cuando se estrena en Madrid Pop y patatas fritas, de Carmen Resino. En 1994 se repone con éxito Tres idiotas españolas, de Lidia Falcón, que se había estrenado en 1987. Del 5 al 8 de octubre de 1994 tuvo lugar en Cincinnati, dirigido por Patricia W. O`Connor y Kirsten Nigro, un «Simposio/festival dedicado a las mujeres españolas, hispanoamericanas y latinas de USA en el teatro», bajo la denominación de «Un escenario propio». Las ponencias y las mesas estuvieron encaminadas a clarificar la situación de las autoras de los dos continentes y supuso una muestra imprescindible de enfoques para analizar el complejo fenómeno de la dramaturgia femenina y de su ocultación hasta hacía pocos años ${ }^{15}$.

Desde los comienzos de la década se van incorporando a los ya existentes otros nombres que se manifiestan, en ocasiones, mediante los premios con los que son distinguidas en concursos de autoría joven o restringidamente femenina. En 1984, desde el Instituto de la Juventud del Ministerio de Cultura, se convoca por primera vez el Premio para jóvenes Marqués de Bradomín; durante los veinte años transcurridos han obtenido accésit del mismo Margarita Sánchez, Carmen Delgado, Yolanda Pallín, Eva Ibernia, Itziar Pascual y Marilia Samper; y el Premio lo obtuvieron, en 2000, Gracia María Morales; y en 2001, Pilar Campos Gallego. El objetivo en esta década ya no será el de conseguir un lugar semejante al de los autores, sino luchar junto a ellos por unos espacios donde mostrarse. Paloma Pedrero afirmaba en 1994, durante un Curso Internacional de la Universidad de Salamanca sobre «Recepción, público y crítica en el teatro español contemporáneo», que "por primera vez la autora teatral viaja en grupo y en la misma clase que los hombres» ${ }^{16}$.

Desde 1994 se convoca, con el patrocinio del Instituto de la Mujer, la Asociación de Directores de Escena y la SGAE, el Premio María Teresa 
León para autoras dramáticas, con lo que son distinguidas las mujeres del resto de los autores de teatro. La edición de los textos premiados que lleva a cabo la ADE y el ámbito hispano que poseen las participantes hace que la nómina de nombres conocidos ensanche su geografía y amplíe sus márgenes cada año.

Nuevas autoras podrían mencionarse a partir, sobre todo, de las publicaciones. En 1993, en un coloquio trascrito en las páginas del número 249 de Primer Acto surgen los nombres de Angélica Lidell Zoo y Soledad Iranzo, junto a otros ya conocidos. En 1994 se publica Mal bajío (accésit del Premio Calderón 1989), una obra que merece mención en estas páginas por suponer, casi por vez primera en nuestra dramaturgia, un rotundo testimonio de la vida dentro de una cárcel de mujeres, escrito por Elena Cánovas, en colaboración con Paula Monmeneu y Victoria Nacario. Cánovas une a la de autora la calidad de directora de escena, actividad que desarrolla con su grupo Yeses llevando a cabo representaciones con presas. Aunque la escritura que se inicia en los talleres es la predominante, algunas autoras de la más joven generación, surgen de manera particular y espontánea; así sucede con Diana de Paco Serrano, que en 1997 resulta premiada por la Universidad de Sevilla, queda finalista del Premio Calderón de la Barca del año 2000 y recibe el Premio Libro Murciano del año en teatro por Lucía y La antesala, en 2002.

En 1996 Candyce Leonard y John P. Gabriele editan dos volúmenes antológicos de teatro de los noventa en donde autores y autoras comparten en paridad el espacio ${ }^{17}$. Otras trayectorias se inician en estos años, como las de Margarita Reiz, Patricia Pọblación, Laila Ripoll, quien, como en otros casos, también es directora de espectáculos. Más presencias surgen en los volúmenes que con esfuerzo, rigor e ilusión viene publicando la Asociación de Autores de Teatro, resultado de sus talleres y encuentros de jóvenes y veteranos representantes de la autoría teatral.

$\mathrm{Al}$ escribir estas líneas hay en cartel varios espectáculos dirigidos por mujeres, reconocidas profesionales en su medio. Alcanza en 2004 su séptima convocatoria el Certamen Nacional de Teatro para Directoras de Escena que se realiza en Torrejón de Ardoz y que premia un espectáculo llevado a cabo por una directora. A la indiscutida y ya clásica Josefina Molina se han ido uniendo, con reconocimiento general, los nombres de María Ruiz, Helena Pimenta o la directora y autora Sara Molina; y algunas de más reciente aparición como Aitana Galán o Ana Zamora.

Una de las últimas manifestaciones de un colectivo de mujeres que integra, según su propia enumeración, «actrices, directoras, escritoras, adaptadoras, técnicas, cantantes, circenses, músicas, bailarinas, perfor- 


\section{Dramaturgia femenina fin de siglo. Estado de la cuestión}

meras, diseñadoras, escenógrafas, vestuaristas, investigadoras, profesoras, coreógrafas, peluqueras, productoras, distribuidoras, iluminadoras, sastras, constructoras...» es el de las Marías Guerreras (Asociación de Mujeres de las Artes Escénicas en Madrid), cuyo rótulo alude como referente principal al nombre de María Guerrero, pero connota una actitud de quienes combaten por dar protagonismo a las mujeres de la escena española, cuyas trayectorias consideran «difundidas escasamente, a pesar de lo notable de sus tareas» ${ }^{18}$. En otros espacios de la geografía del país existen grupos de intenciones afines a las Guerreras: Sorámbulas, de Alicante; Proyecte Vaca, de Barcelona; Federicas, de Granada; o AMAE, de Málaga.

En todo este panorama hay quienes se mueven en la creación del texto en fórmulas realistas de construcción; mientras que otras, procedentes de las nuevas promociones de los noventa, prefieren estéticas de mayor libertad poética, ruptura y abstracción. En general, se aprecia una tendencia a expresar la insatisfacción que genera la falta de ideales; la hostilidad y la incomunicación, el miedo y la violencia que afectan a las relaciones entre los individuos; males todos de una sociedad injusta. En los últimos años se produce un intento de recuperar la memoria histórica del pasado más próximo y, en particular, la memoria de las mujeres, célebres o anónimas que lo poblaron. Las más recientes convulsiones políticas y sociales han propiciado un teatro de «urgencia» contra la guerra, el terrorismo, la xenofobia, la violencia ejercida en el propio hogar, temas éstos que, sin ser privativos de la dramaturgia de mujeres, son cultivados por ellas en publicaciones o espectáculos de formato alternativo. Hace años llamábamos la atención sobre la predilección de las autoras por la pieza breve y por el monólogo que permite recoger en tiempo y espacio el momento de una vida o la confesión de un espíritu atormentado ${ }^{19}$; tales formatos no han perdido vigencia, por el contrario, autoras y autores lo cultivan con profusión, de forma individual o como resultado de propuestas de escritura colectiva.

Es frecuente que las creadoras de las décadas a las que nos estamos refiriendo elijan el pasado histórico o mítico para expresar mediante personajes del ayer problemas de hoy, en la línea de teatro histórico abierta por Antonio Buero Vallejo en los ya lejanos años cuarenta. La historia y el mito, revisados y reutilizados, proyectan un subtexto del que brota la conexión actual por lo que los personajes y situaciones constituyen además símbolos de la opresión, de la víctima, del poder, de la lucha: de todos los profundos conflictos que han afectado a seres de cualquier tiempo. 
Aunque algunos de los dramaturgos más comprometidos de las décadas anteriores a nuestro estudio transgredieron el canon de construcción de personajes femeninos según los modelos de madre, esposa, hija, mujer fatal, y construyeron heroínas rebeldes ante las imposiciones del patriarcado, es indudable que la presencia colectiva de la mujer en el territorio de la autoría teatral ha proyectado una nueva mirada que procede de una cosmovisión distinta; aquélla que, al estar en la otra parte, necesariamente tendrá que percibir la realidad con unos matices que no son los habituales para el modelo establecido. Dicha diferencia será más visible en las piezas que se acercan a los conflictos del presente desde una dramaturgia de signo feminista. La elección del personaje femenino en lucha por encontrar su lugar en un mundo organizado a sus espaldas dará como resultado soluciones temáticas y dramatúrgicas inhabituales. Y si bien es cierto que, cuando la dramaturga opta por temas de carácter metafísico o social de amplio significado, su talante femenino se diluye en lo general de los planteamientos, no lo es menos que cuando aborda el tema de la condición femenina su lenguaje se hace específico y las piezas adquieren valores testimoniales, subversivos y transgresores que, por fortuna para todos, han asumido ya también los dramaturgos coetáneos independientemente de la edad que tengan.

\section{Notas}

1 Manuel Serrano Sanz, Apuntes para una biblioteca de escritoras españolas desde el año 1401 al 1833, Madrid, Biblioteca de Autores Españoles, 1903.

$2 \mathrm{Al}$ respecto puede verse Patricia W. O'Connor, Mito y realidad de una dramaturga española: María Martínez Sierra, Logroño, Instituto de Estudios Riojanos, 2003. Prólogo de Virtudes Serrano. Para un panorama de la actividad dramatúrgica de la mujer en el primer tercio de siglo vid. Pilar Nieva de la Paz, Autoras dramáticas españolas entre 1918 y 1936, Madrid, CSIC, 1993.

3 Vid. Juan Antonio Hormigón, dir., Directoras en la Historia del Teatro Español 1550-2002, Madrid, ADE, 2003. A partir de la normalización de la presencia de la mujer en el panorama teatral de la España democrática, la Asociación de Directores de Escena (ADE) había comenzado a publicar su catálogo de autoras (Juan Antonio Hormigón, dir., Autoras en la historia del teatro español I, II, III y IV, Madrid, ADE, 1996, 1997, 2000. Sin embargo, en 1984, María José Ragué Arias («El teatro feminista, o el no-teatro no-feminista», Estreno, X, otoño, 1984, [p.47]) advertía de la escasa presencia aún de directoras y de la falta de compromiso con la mujer que en la mayor parte de sus montajes se percibía: «Existen, eso sí, algunas mujeres que dirigen: Lourdes Ortiz, [...] María Luisa Oliveira y Armonía Rodríguez, Eugenia Casanovas, Asun Rodríguez, Elisa Díaz, Montserrat Julió, Carme Portaceli, Pilar Laveaga... pocas son las que quedan en el olvido, pero aun las pocas mencionadas, o no se plantean la alternativa feminista, o si lo hacen, trabajan en condiciones de gran marginalidad". 


\section{Dramaturgia femenina fin de siglo. Estado de la cuestión}

${ }^{4}$ Entre ellas se encontraba Lidia Falcón, quien toma parte activa en el movimiento de las escritoras dramáticas de los ochenta y desde entonces dedica parte de su escritura a este género.

5 Teresa Gracia, Las republicanas, Madrid, Pre-Textos, 1982; y Casas viejas y Una mañana, una tarde y una vida de la señorita Pura, Madrid, Endymión, 1992. He realizado un análisis de estas obras en "La expresión dramatúrgica de Teresa Gracia: vida y territorio", en Manuel Aznar Soler, ed., El exilio teatral republicano de 1939, Barcelona, Gexel, 1999, pp. 379-390.

6 Por entonces, preparaba la investigadora norteamericana su primer libro sobre la pareja formada por Gregorio y María Martínez Sierra (Gregorio y María Martínez Sierra: crónica de una colaboración, Madrid, La Avispa, 1987) y su relación con la librera-editora Julia García Verdugo seguramente facilitó para ella el conocimiento de las autoras que en buena medida se reunían en la librería y depositaban allí sus inéditos. Gracias a la gentileza de Julia García Verdugo, yo misma tuve acceso a muchos de los textos de aquellos primeros años y al conocimiento de sus autoras.

7 Publicada en Madrid, Centro Español del Instituto Internacional del Teatro, 1983, con texto de presentación de Antonio Gala, p. 3, y «Nota preliminar» de la autora, p. 7, ha sido editada nuevamente en Carmen Resino, Teatro diverso (1973-1972): Ulises no vuelve. La recepción. De película, ed. de Virtudes Serrano, Cádiz, Universidad, Serie 2, 2001.

8 Producto de estas jornadas de análisis fue el volumen La escritura teatral a debate, Madrid, CNNTE, 1985.

9 Patricia W O' Connor, Dramaturgas españolas de hoy (Una introducción), Madrid, Fundamentos, 1988.

10 Puede verse también «Maribel Lázaro, el sueño del 'Calderón de la Barca'» El Público, 30, marzo 1986, p. 4.

11 El estreno tuvo lugar el 5 de noviembre de 1985, en el Centro Cultural de la Villa de Madrid, dirigido por Alberto Wainer. Desempeñó el papel de la protagonista la propia autora. 41.

12 María Victoria Oliva, "Las dramaturgas se asocian», El Público, 43, abril 1987, p.

13 Vid. Virtudes Serrano, "Hacia una dramaturgia femenina", Anales de la Literatura Española Contemporánea, 19, 3, 1994, pp. 343-364 y “Memoria y autobiografía en la dramaturgia femenina actual", en José Romera Castillo, ed., Teatro y memoria en la segunda mitad del siglo XX, Madrid, Visor, 2003, pp. 47-62.

14 Lourdes Ortiz, “Nuevas autoras», Primer Acto, 220, septiembre-octubre 1987, pp. $10-21$.

15 Una selección de las intervenciones puede verse en Kirsten Nigro y Phillys Zatlin, eds., Un escenario Propio. A Stage of Their Own (Actas selectas), Ottawa, Girol Books Inc., 1998.

16 Algunas autoras imparten ya talleres de creación. Juan Mayorga y Jesús Gonzalo, participantes en el Coloquio "Seis autores de los noventa" (Primer Acto, 249, mayo-junio 1993, 35-36), afirman que han recibido clases de dramaturgia de Paloma Pedrero.

17 Candyce Leonard y John P. Gabriele, eds., Panorámica del teatro español actual y Teatro de la España demócrata: los noventa, Madrid, Fundamentos, 1996. En este mismo sentido puede verse Teatro breve entre dos siglos. Antología, ed. de Virtudes Serrano, Madrid, Cátedra, 2002.

18 Itziar Pascual y Nieves Mateo, “Las Marías Guerreras. Retrato de mujeres sin sombras", en Itziar Pascual, Esperanza de la Encarnación y Margarita Reiz, eds., I Ciclo 


\section{Virtudes Serrano}

572

de Las Marías Guerreras en Casa de América, Madrid, 2004, pp. 11-24. Vid. también "Mujeres en escena", Primer Acto, 302, enero-marzo, 2004, pp. 56-113.

19 Virtudes Serrano, "La pieza breve en la última dramaturgia femenina", Art Teatral, 5, 1993, pp. 93-97. 